\section{Treatment of essential thrombocythemia in Europe: a prospective long-term observational study of 3649 high-risk patients in the Evaluation of Anagrelide Efficacy and Long-term Safety study}

\author{
Gunnar Birgegård, ${ }^{1}$ Carlos Besses, ${ }^{2}$ Martin Griesshammer, ${ }^{3}$ Luigi Gugliotta, ${ }^{4}$ \\ Claire N. Harrison, ${ }^{5}$ Mohamed Hamdani, ${ }^{6}$ Jingyang Wu, ${ }^{6}$ Heinrich Achenbach ${ }^{7}$ \\ and Jean-Jacques Kiladjian ${ }^{8}$
}

${ }^{1}$ Department of Haematology, Institute for Medical Sciences, Uppsala University, Sweden; ${ }^{2}$ Department of Hematology, Hospital del Mar-IMIM, Barcelona, Spain; ${ }^{3}$ Hematology and Oncology, Johannes Wesling Medical Center, Minden, Germany; ${ }^{4}$ Department of Haematology, 'L e A Seragnoli', Sant'Orsola-Malpighi Hospital, Bologna, Italy; ${ }^{5}$ Department of Haematology, Guy's and St Thomas' NHS Foundation Trust, London, UK; 'Global Biometrics, Shire Pharmaceuticals, Lexington, MA, USA; ${ }^{7}$ Research \& Development, Shire $\mathrm{GmbH}$, Zug, Switzerland and ${ }^{8}$ APHP, Hopital Saint-Louis, Paris, France

\section{ABSTRACT}

E valuation of Anagrelide $\left(\right.$ Xagrid $\left.^{\circledR}\right)$ Efficacy and Long-term Safety, a phase IV, prospective, non-interventional study performed in 13 European countries enrolled high-risk essential thrombocythemia patients treated with cytoreductive therapy. The primary objectives were safety and pregnancy outcomes. Of 3721 registered patients, 3649 received cytoreductive therapy. At registration, 3611 were receiving: anagrelide $\left(\right.$ Xagrid $\left.^{\top}\right)(n=804)$, other cytoreductive therapy $(n=2666)$, or anagrelide + other cytoreductive therapy $(n=141)$. The median age was 56 vs. 70 years for anagrelide vs. other cytoreductive therapy. Event rates (patients with events/100 patient-years) were 1.62 vs. 2.06 for total thrombosis and 0.15 vs. 0.53 for venous thrombosis. Anagrelide was more commonly associated with hemorrhage (0.89 vs. 0.43), especially with anti-aggregatory therapy (1.35 vs. 0.33$)$ and myelofibrosis (1.04 vs. $0.30)$. Other cytoreductive therapies were more associated with acute leukemia (0.28 vs. 0.07$)$ and other malignancies (1.29 vs. 0.44). Post hoc multivariate analyses identified increased risk for thrombosis with prior thrombohemorrhagic events, age $\geq 65$, cardiovascular risk factors, or hypertension. Risk factors for transformation were prior thrombohemorrhagic events, age $\geq 65$, time since diagnosis, and platelet count increase. Safety analysis reflected published data, and no new safety concerns for anagrelide were found. Live births occurred in 41/54 pregnancies (76\%). clinicaltrials.gov Identifier: 00567502.

\section{Introduction}

Essential thrombocythemia (ET) is associated with an increased risk of thrombohemorrhagic complications and transformation to myelofibrosis (MF) or acute leukemia (AL). ${ }^{1}$ Cytoreductive therapy (CRT) is used to reduce thrombosis and hemorrhage in high-risk ET. ${ }^{2}$ European LeukemiaNet recommends hydroxycarbamide (HC) as first-line therapy, but advises caution in patients $<40$ years. ${ }^{2}$ Anagrelide $\left(\mathrm{Xagrid}^{\circledR}\right)$ is licensed in Europe for patients with ET intolerant/refractory to $\mathrm{HC}, 2,3$ and in some countries (i.e., USA, Japan) it is authorized as first-line therapy.

CRT decreases thrombosis upon the reduction and control of platelet counts. ${ }^{4}$ HC carries a potential leukemogenic risk; however, this remains a matter of debate ${ }^{5.7}$ Few prospective studies have been conducted to compare the effect of different CRT therapies on complications in $\mathrm{ET}^{8,9}$ or to report on the long-term safety outcomes. Herein, we report final data from the Evaluation of Anagrelide Efficacy and Long-term Safety (EXELS) study, the largest prospective study in high-
Haematologica 2018

Volume 103(1):51-60

\section{Correspondence:}

gunnar.birgegard@medsci.uu.se

Received: June 20, 2017.

Accepted: October 25, 2017.

Pre-published: October 27, 2017.

doi:10.3324/haematol.2017.174672

Check the online version for the most updated information on this article, online supplements, and information on authorship \& disclosures: www.haematologica.org/content/103/1/51

\section{(C)2018 Ferrata Storti Foundation}

Material published in Haematologica is covered by copyright. All rights are reserved to the Ferrata Storti Foundation. Use of published material is allowed under the following terms and conditions:

https://creativecommons.org/licenses/by-nc/4.0/legalcode. Copies of published material are allowed for personal or internal use. Sharing published material for non-commercial purposes is subject to the following conditions:

https://creativecommons. org//icenses/by-nc/4.0/legalcode, sect. 3. Reproducing and sharing published material for commercial purposes is not allowed without permission in writing from the publisher. 
risk ET patients treated with CRT, including post hoc multivariate analyses identifying risk factors for thrombohemorrhagic events, and transformation to MF and AL.

\section{Methods}

\section{Trial design}

EXELS is a phase IV, prospective, non-interventional, postauthorization, multicenter cohort study which was conducted in 125 centers in 13 European countries from May 2005 to April 2014. The results represent the final data from the 5 -year observation period. High-risk ET patients (age $>60$ years, prior thrombosis/hemorrhage, or platelets $>1000 \times 10^{9} / \mathrm{L}$ ) were eligible if receiving/scheduled to receive CRT. The Polycythemia Vera Study Group (PVSG) $)^{10}$ or the World Health Organization (WHO) 2001/2008 ${ }^{11}$ diagnostic criteria were used. As an observational study, the protocol could not mandate mutation analysis; however, investigators were encouraged to report JAK2 status. Written informed consent was obtained from all participants in accordance with the Declaration of Helsinki.

\section{Treatment}

CRT was determined prior to registration. Patients could be newly diagnosed or continuing prior CRT, including anagrelide, $\mathrm{HC}$, busulfan, interferon- $\alpha$ (IFN), pegylated interferon, pipobroman and sodium phosphate (P32). Patients could receive concomitant anti-aggregatory (A-A) therapy and have CRT changed at any time at the investigator's discretion.

\section{Objectives}

The primary objective was safety and pregnancy outcomes with anagrelide vs. other CRTs in high-risk ET patients in routine clinical practice. The secondary objective was to evaluate efficacy, as measured by the incidence of thrombotic/hemorrhagic events, and platelet counts.

\section{Data capture}

Data were collected at registration and every 6 months for 5 years. Suspected serious adverse reactions (SSARs) and predefined events (PDEs) of specific interest in this study were recorded. An independent event validation panel blinded to CRT validated PDEs for consistent/correct PDE group allocation. Study conduct/monitoring was overseen by a steering committee and an independent data and safety monitoring board.

\section{Statistical methods}

Patients receiving a treatment for $\geq 1$ day were allocated to treatment groups. The safety population included patients receiving $\geq 1$ dose of CRT, analyzed as: 1) first-treatment analysis; PDEs or SSARs that occurred before a patient switched CRT, and 2) overall-treatment analysis; PDEs or SSARs allocated to the treatment at time of event. Patients could be included in more than one treatment group; as such the number of events is higher in the overall - vs. first-treatment group.

Data were analyzed according to 'anagrelide only', 'other CRT', and 'anagrelide + other CRT'. Patients with multiple events of the same PDE/SSAR category were counted once for each treatment received. Selected PDEs were combined into the following five endpoints: 1) all major thrombotic events (arterial plus venous), 2) arterial thrombotic events, 3) venous thrombotic events, 4) major hemorrhagic events, and 5) thrombohemorrhagic events (all major thrombotic/hemorrhagic events). Event rates were calculated as the number of affected patients per 100 patient-years exposure.

\section{Multivariate analysis}

Two post hoc multivariate analyses were performed, first for the overall group in order to evaluate potential risk factors (except treatment) for thrombotic/hemorrhagic events, and death, and second for the first-treatment group to investigate risk factors and treatment effect for thrombotic/hemorrhagic events and MF transformation. Regression analysis followed the strategy for model selection. ${ }^{12}$ The final model was fit by using a significance level of 0.05 . To facilitate interpretation, "significant" is used for "variable" or "variable treatment" interaction term significant at $P \leq 0.001$ level as no multiplicity adjustment was made.

\section{Results}

\section{Patients}

The EXELS study included 3721 patients from 13 European countries. At time of registration, 110 patients were not receiving CRT and were excluded from the first-treatment safety population $(n=3611)$. Of these, 38 subsequently received CRT and were included in the overall-treatment safety population ( $\mathrm{n}=3649$; Online Supplementary Figure S1). 66\% of the patients were diagnosed according to WHO diagnostic criteria, 29\% were diagnosed by PVSG diagnostic criteria, and 5\% were diagnosed by unknown criteria.

Baseline characteristics in the first-treatment safety population are shown in Table 1. Anagrelide was more frequently used in younger patients (Figure 1). Median age was therefore lower in the 'anagrelide' (55.5 years, range: 18-89) and 'anagrelide + other CRT' (59.0 years, range: 22-88) vs. the 'other CRT' groups (70.0 years, range: 17-95). At baseline, the proportion of patients with prior thrombohemorrhagic events were similar at $25-30 \%$ across treatment groups (Table 1). More than $80 \%$ of patients received either HC $(n=2341)$ or anagrelide $(n=804)$ therapy. In the safety population, median duration of exposure was 1717.0 days (range: 1-2573) and 1481.0 days (range: $1-2677$ ) in the ' $\mathrm{HC}$ ' and 'anagrelide' groups, respectively. Exposure to $\mathrm{HC}$ and anagrelide was 10377 and 4320 patient-years, respectively. IFN was used by 136 patients, and monotherapy with busulfan, pipobroman or P32 by $<5 \%$ together; therefore, outcome analyses were not performed for these subgroups. A-A was used by $58.1 \%$ in the 'anagrelide' group and $72.8 \%$ in the 'other CRT' group. JAK2V617F mutation status was reported in too few patients to allow for statistical analysis.

\section{Complications as predefined events}

The recorded PDEs included complications of the disease, adverse effects of treatment and non-related adverse events (Table 2). In the first treatment analysis population the most common PDEs (apart from thrombosis and hemorrhage) in the 'anagrelide' group were cardiovascular symptoms (i.e., palpitations and tachycardia), and in the 'other CRT' group non-hematological malignancies and non-PDE death. The same pattern was seen in the overall-treatment population (Online Supplementary Table S1).

The most common cardiovascular events, tachycardia $(2.0 \%$ vs. $0.1 \%)$ and palpitations $(1.7 \%$ vs. $0.2 \%)$, were reported with more frequency in the 'anagrelide' vs. 'other CRT' group (Online Supplementary Table S2). Arrhythmias consisted almost exclusively of atrial fibrilla- 
tion, which showed similar event rates (0.30 vs. 0.33$)$ in both groups (Online Supplementary Table S1). Ventricular tachycardia and ventricular fibrillation was recorded in one patient each in the 'other CRT' group. Cardiac failure was reported in a very low proportion of patients in the 'anagrelide' and 'other CRT' groups (both $<0.1 \%$, event rates: 0.37 vs. 0.32 ; Table 2 ).

\section{Suspected serious adverse reactions}

The SSAR event rate was low across all treatments, albeit slightly higher in the 'anagrelide' vs. 'other CRT' group, at 0.86 vs. 0.60, respectively (Online Supplementary Table S3). This difference was predominantly caused by cardiac events, and to a lesser extent by gastrointestinal disorders. No unexpected side effects were noted for anagrelide.

\section{Death}

In the overall safety population, 439 patients (12.0\%) died. ET-related deaths included transformation (70; $1.9 \%)$, myocardial infarction $(33 ; 0.9 \%)$, major hemorrhagic event $(21 ; 0.6 \%)$ and stroke $(19 ; 0.5 \%)$. The causes of non-ET-related death included non-hematological malignancy $(57 ; 1.6 \%)$ and cardiac failure $(20 ; 0.5 \%)$. In 188 patients $(5.2 \%)$, death was not assigned a PDE category and comprised of: an unknown reason (108), sepsis/infection (24), respiratory/pulmonary diseases (22), natural death/deterioration of health status (20), cardiovascular disease (11), and cancer (3).

\section{Pregnancy}

Fifty-four pregnancies (40 patients) occurred. Nine patients had no therapy, 24 had IFN (one patient had

Table 1. Patient demographic and baseline characteristics: first treatment analysis population.

\begin{tabular}{|c|c|c|c|}
\hline IIreatment at registration & $\begin{array}{c}\text { Anagrelide } \\
\mathrm{N}=804\end{array}$ & $\begin{array}{l}\text { Other CRT } \\
\mathrm{N}=2666\end{array}$ & $\begin{array}{l}\text { Anagrelide + other CRT } \\
\qquad N=141\end{array}$ \\
\hline \multicolumn{4}{|l|}{ Age, years } \\
\hline Median & 55.5 & 70 & 59 \\
\hline Range & $18-89$ & $17-95$ & $22-88$ \\
\hline \multicolumn{4}{|c|}{ Age categories (years), n (\%) } \\
\hline$<65$ years & $575(71.5)$ & $913(34.3)$ & $89(63.1)$ \\
\hline $65-<75$ years & $133(16.5)$ & $897(33.7)$ & 30 (21.3) \\
\hline$\geq 75$ years & $96(11.9)$ & $854(32.1)$ & $22(15.6)$ \\
\hline \multicolumn{4}{|l|}{ Gender, n (\%) } \\
\hline Male & $303(37.7)$ & $1032(38.7)$ & $61(43.3)$ \\
\hline Female & $501(62.3)$ & $1632(61.3)$ & $80(56.7)$ \\
\hline \multicolumn{4}{|c|}{ Clinically significant vascular risk factor present, $\mathrm{n}$ (\%) } \\
\hline Yes & $441(54.9)$ & $1814(68.0)$ & $79(56.0)$ \\
\hline Hypertension & $268(33.3)$ & $1260(47.3)$ & $48(34.0)$ \\
\hline Diabetes & $41(5.1)$ & $211(7.9)$ & $8(5.7)$ \\
\hline Hypercholesterolemia & $114(14.2)$ & $500(18.8)$ & $16(11.3)$ \\
\hline Smoking & $122(15.2)$ & $346(13.0)$ & $34(24.1)$ \\
\hline Other & $96(11.9)$ & $351(13.2)$ & $16(11.3)$ \\
\hline \multicolumn{4}{|c|}{ Overall normal cardiac function, $\mathrm{n}(\%)$} \\
\hline Yes & $587(73.0)$ & $1649(61.9)$ & $104(73.8)$ \\
\hline \multicolumn{4}{|c|}{ Currently taking aspirin, $\mathrm{n}(\%)$} \\
\hline Yes & $467(58.1)$ & $1942(72.8)$ & $91(64.5)$ \\
\hline \multicolumn{4}{|c|}{ Any significant hemorrhagic/thrombotic events prior to registration, n (\%) } \\
\hline Yes & $202(25.1)$ & $768(28.8)$ & $43(30.5)$ \\
\hline \multicolumn{4}{|l|}{ Baseline platelet count } \\
\hline $\mathrm{n}$ & 703 & 2344 & 125 \\
\hline Median $\left(10^{9} / \mathrm{L}\right)$ & 453 & 432 & 494 \\
\hline Range $\left(10^{9} / \mathrm{L}\right)$ & $36-2226$ & $114-2020$ & 220-1816 \\
\hline \multicolumn{4}{|l|}{ Baseline white blood cells } \\
\hline $\mathrm{n}$ & 230 & 616 & 43 \\
\hline Median $\left(10^{9} \mathrm{~L}\right)$ & 8.7 & 6.1 & 7.6 \\
\hline Range $\left(10^{9 / L}\right)$ & $3.22-31.30$ & $2.0-34.19$ & $2.9-43.50$ \\
\hline \multicolumn{4}{|l|}{ Baseline hemoglobin } \\
\hline $\mathrm{n}$ & 281 & 743 & 52 \\
\hline Median (g/dL) & 12.8 & 13.0 & 12.3 \\
\hline Range (g/dL) & $5.5-17.3$ & $8.2-18.6$ & $8.0-16.0$ \\
\hline
\end{tabular}


$\mathrm{HC}+\mathrm{IFN}$ ), 10 had anagrelide, eight had A-A, and three were receiving anticoagulant without CRT at the time that pregnancy was reported. Most patients on IFN or no therapy continued without change during pregnancy. There were five terminations in five patients; three patients had six miscarriages (all but one during the first trimester) and the outcome was missing for two pregnancies. There were 41 live births reported (75.9\% of the pregnancies), all with normal birth weight (range: $2.4-4.7 \mathrm{~kg}$ ).

\section{Thrombotic and hemorrhagic events}

In the first-treatment analysis group, the event rate for major thrombosis was lower in the 'anagrelide' vs. the 'other CRT' group (1.62 vs. 2.06; Table 3). Arterial thrombotic event rates were similar between the 'anagrelide' and 'other CRT' group (1.47 vs. 1.55), whereas the venous thrombotic rate was lower in the 'anagrelide' compared with the 'other CRT' group (0.15 vs. 0.53). The major hemorrhagic event rate was higher in the 'anagrelide' group (0.89 vs. 0.43), especially in patients treated with A-A (1.35 vs. 0.33, respectively). The composite thrombohemorrhagic event rate was slightly higher in the 'anagrelide' (2.47) compared to 'other CRT' (2.41) group, largely due to hemorrhagic events. Similar results for thrombosis and hemorrhage event rates were observed in the overall treatment analysis group (Online Supplementary Table S4).

\section{Transformation and malignancies}

In the first-treatment analysis, 64 patients transformed to $\mathrm{MF}, 31$ to $\mathrm{AL}$, and 12 to myelodysplastic syndrome (MDS; Table 4). The rate of transformation to MF was higher in the 'anagrelide' compared with the 'other CRT' group (1.04 vs. 0.30). Transformation to AL was higher in the 'other CRT' compared with the 'anagrelide' group (0.28 vs. 0.07), and transformation to MDS only occurred in the 'other CRT' group (event rate: 0.12 ). Similar proportions were seen in the overall treatment analysis (Table 4). For patients who had only ever received one type of CRT, the rate of transformation to $\mathrm{MF}$ was still higher in the 'anagrelide' compared with the 'HC' group (0.61 vs. 0.14); the median time to transformation was similar, around 7 years (range: $0.95-20.62$ ). The rate of transformation to
AL in the 'anagrelide' group was 0 vs. 0.22 in patients treated with HC alone, while the median time to transformation was 6.48 years from diagnosis (range: 1.21-22.09) for the ' $\mathrm{HC}$ ' group. High platelet levels at baseline were identified in the multivariate analysis as a risk factor for $\mathrm{MF}$ transformation (hazard ratio [HR] 1.18, $P=0.0004$ ); the risk of $\mathrm{MF}$ increased for each increased platelet count of $100 \times 10^{9} / \mathrm{L}$.

The rate of non-hematological malignancies was lower in the 'anagrelide' vs. 'other CRT' group, both in the first-treatment (0.44 vs. 1.29; Table 2) and overall-treatment analysis groups (0.49 vs. 1.35; Online Supplementary Table S1).

\section{Blood counts}

Platelet levels were well controlled throughout the study across treatment groups (Figure 2). The median counts for 'anagrelide' and 'other CRT' were $431 \times 10^{\circ} / \mathrm{L}$ and $413 \times 10^{9} / \mathrm{L}$ at 6 months, respectively, and $390 \times 10^{9} / \mathrm{L}$ and $404 \times 10^{9} / \mathrm{L}$ at 5 years, respectively. In patients who experienced a major thrombotic event, median platelet counts ranged from 402 to $430 \times 10^{9} / \mathrm{L}$ at the time of event, and the percentages of patients with a platelet count $\leq 450 \times 10^{9} / \mathrm{L}$ or $>600 \times 10^{9} / \mathrm{L}$ were similar in patients with and without thrombosis (data not shown). As expected, median white blood cell (WBC) counts were lower at registration in the 'other CRT' group $\left(6.1 \times 10^{9} / \mathrm{L}\right)$ compared with the 'anagrelide' $\left(8.7 \times 10^{\circ} / \mathrm{L}\right)$ and 'anagrelide + other CRT' $\left(7.6 \times 10^{\circ} / \mathrm{L}\right)$ groups (Table 1$)$ throughout the study, and remained relatively stable over time (Figure 2 ). The WBC count $>15 \times 10^{9} / \mathrm{L}$ at any time prior to thrombosis was seen in $4.3 \%(n=14 / 327)$ compared with $4.9 \%$ $(n=162 / 3322)$ in patients without thrombosis. The amount of reported WBC data was too low to allow for a Cox regression analysis of any correlation between WBC counts and thrombosis. Notably, $11.4 \% \quad(n=50 / 439)$ of patients who died during the study had a WBC count $>15 \times 10^{9} / \mathrm{L}$ at any time prior to death vs. $4.2 \%$ ( $n=135 / 3210)$ of patients who remained alive. Median hemoglobin levels remained stable throughout the study across all treatment groups (Figure 2), with ranges of 12.3$13.0 \mathrm{~g} / \mathrm{dL}$ at registration and $12.0-13.0 \mathrm{~g} / \mathrm{dL}$ at 5 years.

Table 2. Cumulative event rates of other predefined events for the first-treatment analysis population.

\begin{tabular}{|c|c|c|c|c|c|c|}
\hline İreatment at registration & & & & $\begin{array}{l}\text { CRT } \\
366\end{array}$ & Anagrell & $\begin{array}{l}\text { ther CRT } \\
1\end{array}$ \\
\hline Predefined event & $\begin{array}{c}\text { Patients } \\
\text { (events) } \\
n\end{array}$ & Event rate & $\begin{array}{c}\text { Patients } \\
\text { (events) } \\
n\end{array}$ & Event rate & $\begin{array}{c}\text { Patients } \\
\text { (events) } \\
\text { n }\end{array}$ & Event rate \\
\hline Congestive heart failure & $10(10)$ & 0.37 & $31(37)$ & 0.32 & $2(2)$ & 0.53 \\
\hline Cardiomyopathy & $4(4)$ & 0.15 & $9(9)$ & 0.09 & 0 & 0 \\
\hline Other cardiovascular symptoms & $47(61)$ & 1.79 & $86(117)$ & 0.90 & $12(12)$ & 3.30 \\
\hline Severe mucocutaneous disorders & $4(4)$ & 0.15 & $63(68)$ & 0.65 & $2(2)$ & 0.54 \\
\hline Pulmonary hypertension & $4(4)$ & 0.15 & $5(5)$ & 0.05 & 0 & 0 \\
\hline Pulmonary fibrosis/interstitial pneumonia & $1(1)$ & 0.04 & $9(10)$ & 0.09 & 0 & 0 \\
\hline Pancreatitis & 0 & 0 & $3(3)$ & 0.03 & 0 & 0 \\
\hline Rhabdomyolysis/myalgia & $2(2)$ & 0.07 & $3(4)$ & 0.03 & 0 & 0 \\
\hline Non-hematological malignancy & $12(13)$ & 0.44 & $123(140)$ & 1.29 & $2(2)$ & 0.54 \\
\hline Non-PDE death* & $18(18)$ & 0.66 & $105(105)$ & 1.08 & $2(2)$ & 0.53 \\
\hline
\end{tabular}

* Deaths not recorded as an outcome of a predefined event. CRT: cytoreductive therapy; PDE: predefined event. 
Multivariate analysis, risk factors for thrombohemorrhagic and transformation events

'Prior thrombohemorrhagic events' and 'age $\geq 65$ years' at baseline were identified as risk factors for major thrombotic, arterial thrombotic, venous thrombotic and total thrombohemorrhagic events (Online Supplementary Table S5). The presence of baseline cardiovascular risk factors was associated with a higher risk of arterial thrombotic events. A higher platelet count at baseline correlated with an increased risk for transformation to MF (HR 1.18, confidence interval [CI] 1.08 to $1.30, P=0.0004)$ for each platelet count increase of $100 \times 10^{\circ} / \mathrm{L}$ at baseline. A lower risk for MF transformation was indicated for patients diagnosed with ET by WHO criteria than those diagnosed by PVSG criteria (HR 0.55, $P=0.03$; Table 5). As expected, a time from diagnosis $>10$ years indicated a higher risk for MF transformation (HR 4.38, CI 1.49 to 12.88 compared with $<1$ year, $P=0.0073$; Table 6 ).

In a separate multivariate analysis conducted in the first treatment analysis group ('anagrelide' vs. 'other CRT'), the influence of treatment on risk for thrombosis and hemorrhage, as well as transformation to MF, was analyzed (Table 5). Anagrelide was associated with a higher risk for major thrombosis (HR 1.68, CI 1.09 to 2.60, $P=0.02$ ) and arterial thrombosis (HR 1.91, CI 1.20 to $3.04, P=0.0067$ ). There was no difference between WHO-defined and PVSG-defined ET in this respect (HR 1.49 vs. 1.45). There was also no difference in risk for arterial thrombosis in general between WHO-defined and PVSG-defined ET. In a Cox regression analysis with arterial events as the outcome and ET diagnosis as the single explanatory variable, HR was 1.06 (CI 0.77 to $1.46, P=0.73$ ).

The risk for MF transformation was greater in the 'anagrelide' vs. 'other CRT' group (HR 3.33, CI 1.94 to 5.73, $P<0.0001)$, but this difference was smaller in WHOdefined than in PVSG-defined ET (HR 2.79, CI 1.24 to 6.27, $P=0.0132$ vs. HR 4.67, CI 2.10 to $10.37, P=0.0002$ ). The risk for MF transformation was also generally lower in WHO-defined than in PVSG-defined ET (Table 5).

The HR for venous thrombosis, on the other hand, was lower (HR 0.43, CI 0.15 to 1.21, $P=0.11$ ), although it did not reach statistical significance. In anagrelide patients, the concomitant use of A-A therapy showed an increased risk of bleeding (HR 3.55, CI 1.96 to 6.44, $P<0.0001$ ), which increased the total thrombohemorrhagic risk (HR 2.46, CI 1.65 to $3.66, P<0.0001$ ). An increased risk for total thrombohemorrhagic events was also seen for anagrelide patients who were smokers (HR 2.34, CI 1.21 to 4.54, $P=0.0118$ ). A similar effect was seen for arterial thrombotic events, where the risk was also greater for patients receiving anagrelide who were smokers (HR 3.18, CI 1.41 to $7.16, P=0.005)$. Furthermore, in patients with no prior thrombohemorrhagic events, the risk for thrombohemorrhagic events was higher with anagrelide treatment than with other CRT (HR 2.20, CI 1.38 to 3.53, $P=0.001$ ). It was confirmed that age $>65$ and previous thrombosis increased the risk of thrombohemorrhagic events. An initial platelet count of $>1000 \times 10^{\circ} / \mathrm{L}$ and hypertension were associated with a risk for hemorrhage.

\section{Discussion}

EXELS represents the largest prospective cohort of patients with ET reported to date, and as such it provides several important real-world insights into the therapeutic management of this disease. Patients receiving anagrelide were younger than those receiving another CRT, likely due to investigators choosing to use anagrelide as first-line therapy in younger patients in order to avoid a transformation related to the potential leukemogenic risk associated with long-term HC treatment. Differences in age may confound analysis of the event rates in the various treatment groups.

\section{Thrombohemorrhagic events}

Importantly, overall thrombohemorrhagic event rates were low with a rate of $<2.5$ independent of therapy, in line with other large studies, and fairly comparable between the 'anagrelide' and 'other CRT' group, consistent with the Anagrelide vs. Hydroxyurea - Efficacy and Tolerability Study in Patients With Essential Thrombocythaemia (ANAHYDRET) study $^{8}$ and the Primary Thrombocythaemia 1 (PT-1) trial. ${ }^{9}$ The total thrombotic event rate was lower in the 'anagrelide' group, which may reflect the age difference between the groups.

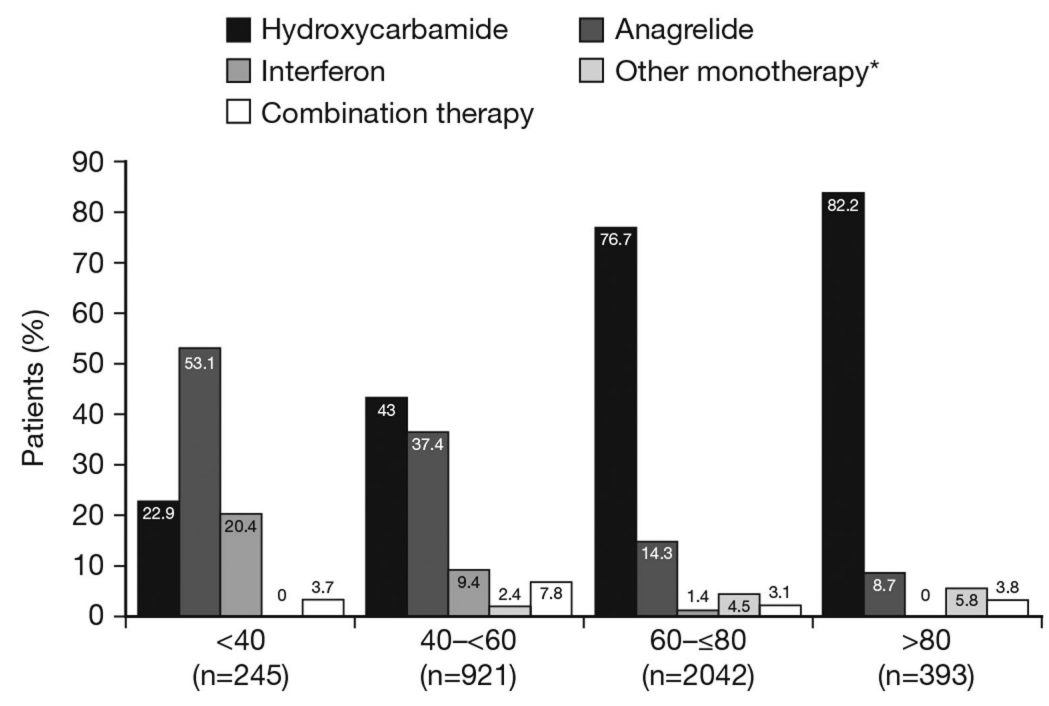

Patient age (years)
Figure 1. Treatment at registration vs. age. Patients in various age groups were treated at registration with anagrelide, hydroxycarbamide, interferon, combination therapy or other monotherapy. *Includes busulfan, interferon, pipobroman, P32, thromboreductin (anagrelide). 
The venous thrombotic event rate was lower in the "anagrelide' group, which supports findings from both the PT1 trial and the ANAHYDRET study. ${ }^{8,9}$ Currently there is no validated explanation for such disparity, but the confirmation in two large studies suggests that the difference warrants further investigation. The hemorrhagic event rate was higher in the 'anagrelide' vs. 'other CRT' group, especially when anagrelide was combined with A-A therapy, which also corresponds with findings from the PT- 1 trial ${ }^{9}$ and underlines the importance of cautious use of this combination, especially in patients with previous hemorrhages. $^{3}$

A protective effect of A-A therapy for thrombosis was seen in the 'other CRT' and 'anagrelide + other' CRT groups, but not in the 'anagrelide' group. A possible explanation for this is that the 'other CRT' patients had more benefit from A-A therapy due to their older age. These results are consistent with current guidelines recommending A-A therapy in high-risk ET patients. A recent systematic review of $\mathrm{A}-\mathrm{A}$ therapy in $\mathrm{ET}^{13}$ reported significant uncertainty regarding evidence for a protective effect against thrombosis. The study herein gives some evidence for such an effect, at least in HC-treated patients. The multivariate analysis did not detect any difference in the efficacy of anagrelide between WHO- vs. PVSG-diagnosed ET.

Table 3. Cumulative event rates of thrombohemorrhagic events by first-treatment analysis population.

\begin{tabular}{|c|c|c|c|c|c|c|}
\hline \multirow{2}{*}{$\begin{array}{l}\text { IIreatment at registration } \\
\text { Predefined event }\end{array}$} & \multicolumn{2}{|c|}{$\begin{array}{l}\text { Anagrelide } \\
\mathrm{N}=804\end{array}$} & \multicolumn{2}{|c|}{$\begin{array}{c}\text { Other CRT } \\
N=2666\end{array}$} & \multicolumn{2}{|c|}{$\begin{array}{l}\text { Anagrelide + other CRT } \\
\qquad N=141\end{array}$} \\
\hline & $\begin{array}{c}\text { Patients } \\
\text { (events) } \\
n\end{array}$ & Event rate & $\begin{array}{c}\text { Patients } \\
\text { (events) } \\
n\end{array}$ & Event rate & $\begin{array}{c}\text { Patients } \\
\text { (events) } \\
\text { n }\end{array}$ & Event rate \\
\hline Major thrombotic events* & $43(52)$ & 1.62 & $194(231)$ & 2.06 & $4(5)$ & 1.09 \\
\hline With A-A & $26(32)$ & 1.88 & $129(151)$ & 1.88 & 0 & 0 \\
\hline Without A-A & $12(13)$ & 1.11 & $47(55)$ & 2.36 & $4(4)$ & 3.34 \\
\hline Arterial thrombotic events & $39(48)$ & 1.47 & $147(175)$ & 1.55 & $4(5)$ & 1.09 \\
\hline With A-A & $25(31)$ & 1.81 & $102(122)$ & 1.48 & 0 & 0 \\
\hline Without A-A & $10(11)$ & 0.92 & $33(36)$ & 1.65 & $4(4)$ & 3.34 \\
\hline Venous thrombotic events & $4(4)$ & 0.15 & $51(56)$ & 0.53 & 0 & 0 \\
\hline With A-A & $1(1)$ & 0.07 & $28(29)$ & 0.40 & 0 & 0 \\
\hline Without A-A & $2(2)$ & 0.18 & $15(19)$ & 0.74 & 0 & 0 \\
\hline Major hemorrhagic events & $24(29)$ & 0.89 & $42(47)$ & 0.43 & $1(1)$ & 0.27 \\
\hline With A-A & $19(22)$ & 1.35 & $23(24)$ & 0.33 & 0 & 0 \\
\hline Without A-A & $3(3)$ & 0.27 & $15(17)$ & 0.74 & $1(1)$ & 0.84 \\
\hline Total thrombohemorrhagic events & $65(81)$ & 2.47 & $226(278)$ & 2.41 & $5(6)$ & 1.37 \\
\hline With A-A & $43(54)$ & 3.13 & $146(175)$ & 2.13 & 0 & 0 \\
\hline Without A-A & $15(16)$ & 1.38 & $61(72)$ & 3.09 & $5(5)$ & 4.32 \\
\hline
\end{tabular}

*Includes both arterial and venous events. A-A: anti-aggregatory; CRT: cytoreductive therapy.

Table 4. Cumulative transformation event rates by first- and overall-treatment analysis populations.

\begin{tabular}{|c|c|c|c|c|c|c|}
\hline \multirow[t]{3}{*}{$\begin{array}{l}\text { Ireatment at registration } \\
\text { (first-treatment analysis) }\end{array}$} & \multicolumn{2}{|c|}{$\begin{array}{c}\text { Anagrelide } \\
\mathrm{N}=804\end{array}$} & \multicolumn{2}{|c|}{$\begin{array}{c}\text { Other CRT } \\
N=2666\end{array}$} & \multicolumn{2}{|c|}{$\begin{array}{l}\text { Anagrelide + other CRT } \\
\qquad N=141\end{array}$} \\
\hline & $\begin{array}{l}\text { Patients } \\
\text { (events) }\end{array}$ & Event rate & $\begin{array}{l}\text { Patients } \\
\text { (events) }\end{array}$ & Event rate & $\begin{array}{l}\text { Patients } \\
\text { (events) }\end{array}$ & Event rate \\
\hline & n & & n & & n & \\
\hline Myelofibrosis & $28(28)$ & 1.04 & $29(29)$ & 0.30 & $7(7)$ & 1.91 \\
\hline Myelodysplasia & 0 & 0 & $12(12)$ & 0.12 & 0 & 0 \\
\hline Acute leukemia & $2(2)$ & 0.07 & 27 (27) & 0.28 & $2(2)$ & 0.53 \\
\hline Other leukemia* & $5(5)$ & 0.18 & $13(13)$ & 0.13 & 0 & 0 \\
\hline $\begin{array}{l}\text { Ireatment at time of event } \\
\text { (overall-treatment analysis) }\end{array}$ & \multicolumn{2}{|c|}{$\begin{array}{l}\text { Anagrelide } \\
N=1127\end{array}$} & \multicolumn{2}{|c|}{$\begin{array}{c}\text { Other CRT } \\
N=2909\end{array}$} & \multicolumn{2}{|c|}{$\begin{array}{l}\text { Anagrelide + other CRT } \\
\qquad N=451\end{array}$} \\
\hline Myelofibrosis & $45(45)$ & 1.31 & $35(35)$ & 0.32 & $11(11)$ & 1.27 \\
\hline Myelodysplasia & $1(1)$ & 0.03 & $14(14)$ & 0.13 & $2(2)$ & 0.23 \\
\hline Acute leukemia & $6(6)$ & 0.17 & $36(36)$ & 0.33 & $4(4)$ & 0.46 \\
\hline Other leukemia* & $5(5)$ & 0.14 & $13(13)$ & 0.12 & $1(1)$ & 0.11 \\
\hline
\end{tabular}

* "Other leukemia” includes chronic myelogenous leukemia and unclassified leukemia. CRT: cytoreductive therapy. 


\section{Transformation}

Transformation to AL was more frequent in the "other CRT' vs. the 'anagrelide' group. All six patients in the 'anagrelide' group who developed AL had previously been treated with HC. In patients who had only ever received anagrelide, there were no cases of AL. Non-hematological malignancies were also less frequent in the 'anagrelide' than in either the 'other CRT' or the 'HC' groups. This warrants further analysis and will be addressed in a separate publication. The multivariate analysis identified both a history of thrombohemorrhagic events and an age of $\geq 65$ years at baseline as risk factors for predicting transformation to AL/MDS events.

Transformation to MF was higher in the 'anagrelide' vs. 'HC' group, in line with data from the PT-1 trial. ${ }^{14}$ In both
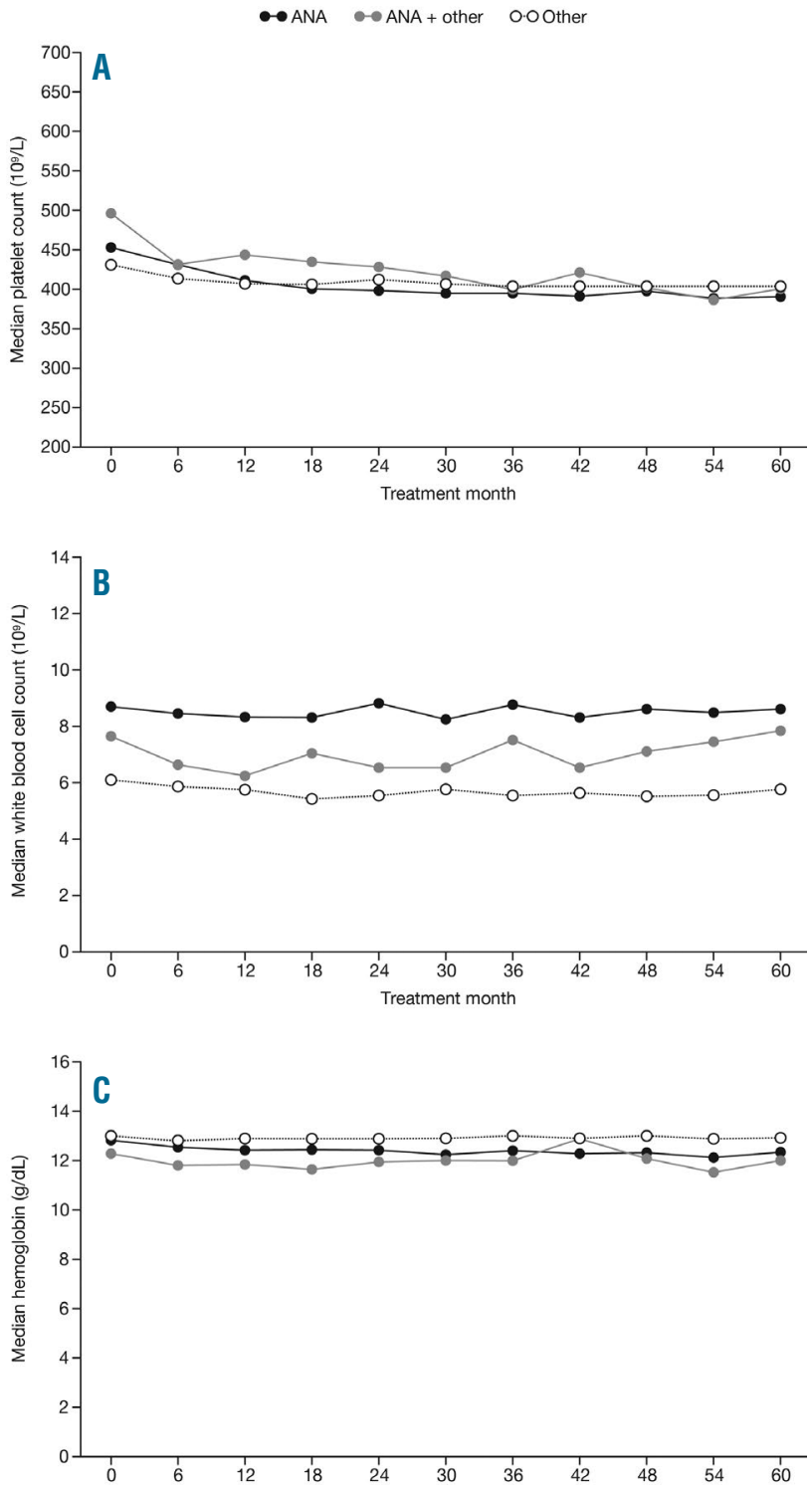

Figure 2. Median blood cell counts over time by first-treatment analysis population. An ad hoc analysis was performed to exclude extreme laboratory data attributed to data entry errors based on the following thresholds: platelet counts of $<10 \times 10^{\circ} / \mathrm{L}$ or $>10,000 \times 10^{9} / \mathrm{L}$, white blood cell counts of $<0.5 \times 10^{\circ} / \mathrm{L}$ or $>150 \times 10^{9} / \mathrm{L}$, hemoglobin of $<5 \mathrm{~g} / \mathrm{dL}$ or $>22 \mathrm{~g} / \mathrm{dL}$, and hematocrit at $<10 \%$ or $>70 \%$. Removal of outliers resulted in similar median results. ANA: anagrelide. studies, patients included those with both 'true ET' according to the WHO classification, as well as ET diagnosed by PVSG criteria, some of whom may have had early MF according to the new WHO criteria ${ }^{11}$ with significant bone marrow fibrosis at entry. This does not explain the difference in the MF transformation event rate, but illustrates that anagrelide does not seem to hinder fibrosis development. Considering the much lower rate of MF development in correctly diagnosed $\mathrm{ET}^{2,15}$ also supported by our results, the optimal patient group for anagrelide treatment could be those with true ET rather than early MF. This is further supported by our finding that the risk for transformation to MF in anagrelide-treated patients was more pronounced in PVSG-defined than in WHOdefined ET. Regular surveillance for features of MF should be considered with anagrelide, especially in patients with primary MF 0-1. A higher platelet count at baseline was identified as a risk factor for MF transformation in the multivariate analysis, a new and interesting finding that requires further confirmation.

Platelet control, white blood cell count and thrombosis

Generally, platelet counts were well controlled throughout the study. No obvious advantage for protection against thrombosis by reducing platelet counts to values below $450 \times 10^{9} / \mathrm{L}$ was seen. Of note, in EXELS, platelet levels were already well controlled at registration. These results suggest that platelet counts do not provide a prognostic value for thrombosis in patients with reasonable platelet control. In contrast, other studies indicate an effect on thrombosis rate by platelet control, ${ }^{16-18}$ and two recent studies show a higher platelet count at time of event for patients with thrombosis. ${ }^{19,20}$ Taken together, it remains uncertain whether reducing platelets to normal levels gives better protection against thrombosis compared with a more tolerant treatment goal. This does not alter the treatment goal in general, but is of importance in situations with moderate treatment efficacy or side effects. Notably, WBC $>15 \times 10^{9} / \mathrm{L}$ did not correlate with thrombotic events, and anagrelide was not associated with a time-dependent hemoglobin-lowering effect.

\section{Safety}

The most common cardiovascular adverse events associated with anagrelide in our study were palpitation and tachycardia, in line with previous reports $\mathrm{s}^{9,7,21}$ and caused by the PDEIII inhibition and positive chronotropic effect of anagrelide. However, the rate of atrial fibrillation was similar for both groups (0.30 vs. 0.33), and other, more severe arrhythmias were rare in both groups. Likewise, heart failure had similar event rates in both groups, which contrast with previous reports that anagrelide may worsen cardiac failure due to the positive chronotropic effect. ${ }^{22}$ The difference in median age between the treatment groups may have contributed to this.

Overall, the SSAR event rate was low, with a slightly higher rate in the 'anagrelide' compared with the 'other CRT' group, predominantly caused by the difference in cardiac event rates for events like tachycardia and palpitations. Cardiac symptoms reported in this study are consistent with the known safety profile for anagrelide. ${ }^{3}$

\section{Pregnancy}

Most subjects became pregnant while receiving IFN or no CRT. Of the 54 pregnancies, $75.9 \%$ resulted in live births, a 
better result than has been seen in many other reports, which may reflect a development in patient management during pregnancy and the selection of patients who chose to become pregnant. Almost all miscarriages occurred during the first trimester, which supports the review of Valera et al..$^{23}$ There were too few miscarriages to make any comparison between treatment groups. The high percentage of successful pregnancies in this large study may support clinicians' decisions to give their patients positive information with regard to the chance for planned childbirth.

Table 5. Results of multivariate regression analysis, first-treatment analysis group, of baseline risk factors for thrombohemorrhagic events and myelofibrosis transformation. Factors with relevant HR difference from 1.

\begin{tabular}{|c|c|c|c|}
\hline Outcome event & Factor & $\begin{array}{l}\text { Hazard ratio } \\
(95 \% \text { CI) }\end{array}$ & $P$ \\
\hline \multirow[t]{7}{*}{ Major thrombotic events } & Treatment (anagrelide $v s$. other) & $1.68(1.09,2.60)$ & 0.0194 \\
\hline & Smoking (yes vs. no) & $1.18(0.76,1.83)$ & 0.4516 \\
\hline & Prior hemorrhagic or vascular events (yes vs. no) & $2.14(1.65,2.78)$ & $<0.0001$ \\
\hline & Age group ( $\geq 65 v s .<65$ years) & $2.19(1.59,3.01)$ & $<0.0001$ \\
\hline & Vascular risk factors (yes vs. no) & $1.40(1.02,1.93)$ & 0.0381 \\
\hline & Smoking=yes, anagrelide $v$ s. other & $3.01(1.41,6.44)$ & 0.0045 \\
\hline & Smoking=no, anagrelide $v s$. other & $0.94(0.63,1.39)$ & 0.7508 \\
\hline \multirow[t]{7}{*}{ Arterial thrombotic events } & Treatment (anagrelide vs. other) & $1.91(1.20,3.04)$ & 0.0067 \\
\hline & Smoking (yes $v s$. no) & $1.18(0.74,1.88)$ & 0.4935 \\
\hline & Prior hemorrhagic or vascular events (yes vs. no) & $1.83(1.37,2.45)$ & $<0.0001$ \\
\hline & Age group ( $\geq 65 v s .<65$ years) & $2.04(1.43,2.91)$ & $<0.0001$ \\
\hline & Vascular risk factors (yes vs. no) & $1.67(1.15,2.42)$ & 0.0074 \\
\hline & Smoking=yes, anagrelide $v s$. other & $3.18(1.41,7.16)$ & 0.0053 \\
\hline & Smoking=no, anagrelide $v$ s. other & $1.14(0.75,1.74)$ & 0.5342 \\
\hline \multirow[t]{3}{*}{ Venous thrombotic events } & Treatment (anagrelide vs. other) & $0.43(0.15,1.21)$ & 0.1099 \\
\hline & Prior hemorrhagic or vascular events (yes vs. no) & $3.29(1.88,5.75)$ & $<0.0001$ \\
\hline & Age group ( $\geq 65$ vs. $<65$ years) & $3.04(1.50,6.16)$ & 0.002 \\
\hline \multirow[t]{7}{*}{ Major hemorrhagic events } & Treatment (anagrelide vs. other) & $1.29(0.69,2.43)$ & 0.4271 \\
\hline & Receiving A-A at start of study (yes vs. no) & $1.37(0.73,2.56)$ & 0.3221 \\
\hline & No A-A at start of study, anagrelide $v$ s. other & $0.47(0.16,1.42)$ & 0.1806 \\
\hline & A-A at start of study, anagrelide $v s$. other & $3.55(1.96,6.44)$ & $<0.0001$ \\
\hline & Initial platelet count >1000x10²/L (yes vs. no) & $2.36(1.42,3.93)$ & 0.001 \\
\hline & Prior hemorrhagic or vascular event (yes vs. no) & $1.64(1.00,2.69)$ & 0.0498 \\
\hline & Hypertension (yes vs. no) & $1.69(1.02,2.79)$ & 0.04 \\
\hline \multirow[t]{12}{*}{ Thrombohemorrhagic events } & Treatment (anagrelide $v s$. other) & $1.51(1.01,2.26)$ & 0.0435 \\
\hline & Smoking (yes vs. no) & $1.22(0.85,1.77)$ & 0.2859 \\
\hline & Receiving A-A at start of study (yes vs. no) & $1.28(0.93,1.75)$ & 0.124 \\
\hline & Prior hemorrhagic or vascular event (yes vs. no) & $1.52(1.14,2.02)$ & 0.0041 \\
\hline & Age group ( $\geq 65$ vs. $<65$ years) & $1.82(1.38,2.39)$ & $<0.0001$ \\
\hline & Vascular risk factors (yes vs. no) & $1.38(1.03,1.84)$ & 0.0305 \\
\hline & Smoking=yes, anagrelide $v$ s. other & $2.34(1.21,4.54)$ & 0.0118 \\
\hline & Smoking=no, anagrelide $v s$. other & $0.98(0.68,1.41)$ & 0.9034 \\
\hline & No A-A at start of study, anagrelide $v$ s. other & $0.93(0.51,1.70)$ & 0.818 \\
\hline & A-A at start of study, anagrelide $v$ s. other & $2.46(1.65,3.66)$ & $<0.0001$ \\
\hline & Prior hemorrhagic or vascular events = yes, anagrelide $v$ s. other & $1.04(0.62,1.73)$ & 0.8845 \\
\hline & Prior hemorrhagic or vascular events = no, anagrelide $v$ s. other & $2.20(1.38,3.53)$ & 0.001 \\
\hline \multirow[t]{6}{*}{ Myelofibrosis transformation } & Treatment (anagrelide vs. other) & $3.33(1.94,5.73)$ & $<0.0001$ \\
\hline & Sex (female $v$ s. male) & $0.74(0.43,1.27)$ & 0.2699 \\
\hline & Sex=female, anagrelide $v$ s. other & $6.04(2.93,12.45)$ & $<0.0001$ \\
\hline & Sex=male, anagrelide $v$ s. other & $1.84(0.82,4.12)$ & 0.14 \\
\hline & ET diagnosis (WHO criteria vs. PVSG criteria) & $0.55(0.33,0.94)$ & 0.0285 \\
\hline & ET diagnosis (Other vs. PVSG criteria) & $0.23(0.03,1.68)$ & 0.1464 \\
\hline
\end{tabular}

A-A: anti-aggregatory; CI: confidence interval; ET: essential thrombocythemia; PVSG: Polycythemia Vera Study Group;WHO:World Health Organization. 
Table 6. Multivariate analysis, overall-treatment population, and significant baseline risk factors for predicting a thrombohemorrhagic or transformation event. Factors with relevant HR difference from 1.

\begin{tabular}{|c|c|c|c|}
\hline Outcome event & Factor & Hazard ratio (95\% Cl) & $P$ \\
\hline \multirow{3}{*}{ Major thrombotic events } & Prior hemorrhagic or vascular events (yes vs. no) & $2.05(1.58,2.66)$ & $<0.0001$ \\
\hline & Age group: $\geq 65$ years us. $<65$ years & $2.14(1.60,2.86)$ & $<0.0001$ \\
\hline & Vascular risk factors: yes vs. no & $1.38(1.01,1.87)$ & 0.0404 \\
\hline \multirow[t]{3}{*}{ Arterial thrombotic events } & Prior hemorrhagic or vascular events: yes vs. no & $1.81(1.36,2.41)$ & $<0.0001$ \\
\hline & Age group: $\geq 65$ years $v s .<65$ years & $1.90(1.38,2.62)$ & $<0.0001$ \\
\hline & Vascular risk factors: yes vs. no & $1.65(1.16,2.35)$ & 0.0055 \\
\hline \multirow[t]{2}{*}{ Venous thrombotic events } & Age group: $\geq 65$ years $v s .<65$ years & $3.70(1.86,7.35)$ & 0.0002 \\
\hline & Prior hemorrhagic or vascular events : yes vs. no & $3.27(1.87,5.72)$ & $<0.0001$ \\
\hline \multirow[t]{3}{*}{ Thrombohemorrhagic events } & Prior hemorrhagic or vascular events : yes vs. no & $1.91(1.52,2.41)$ & $<0.0001$ \\
\hline & Age group: $\geq 65$ years $v s .<65$ years & $1.67(1.29,2.17)$ & $<0.0001$ \\
\hline & Hypertension : yes vs. no & $1.33(1.04,1.69)$ & 0.0207 \\
\hline \multirow[t]{4}{*}{ Myelofibrosis transformation } & Time since diagnosis $: \geq 10$ years $v s .0-<1$ years & $4.38(1.49,12.88)$ & 0.0073 \\
\hline & Time since diagnosis : $5-<10$ years vs. $0-<1$ years & $3.38(1.16,9.81)$ & 0.0254 \\
\hline & Time since diagnosis : $1-<5$ years vs. $0-<1$ years & $1.54(0.52,4.59)$ & 0.4333 \\
\hline & Platelets at baseline (100 units increase) & $1.18(1.08,1.30)$ & 0.0004 \\
\hline \multirow[t]{2}{*}{ AL/MDS transformation } & Prior hemorrhagic or vascular events : yes vs. no & $2.17(1.18,4.01)$ & 0.0127 \\
\hline & Age group: $\geq 65$ years $v s .<65$ years & $3.36(1.56,7.26)$ & 0.002 \\
\hline
\end{tabular}

AL: acute leukemia; CI: confidence interval; MDS: myelodysplastic syndrome.

\section{Multivariate risk factor analysis}

Multivariate analyses were performed both in the overall- and first-treatment populations. These were post hoc analyses and results must therefore be interpreted with caution; however, given the age imbalance between the patient populations, the data are important to assess alongside the event rates. Risk factors identified for thrombohemorrhagic events and for major thrombosis included age, history of thrombosis or hemorrhage, and cardiovascular risk factors, previously reported in retrospective studies. ${ }^{24-28}$ In line with the International Prognostic Score of thrombosis in World Health Organization-essential thrombocythemia (IPSET-thrombosis) risk score model, ${ }^{24}$ the WBC count was not indicative of higher thrombosis risk. Platelets $>1000 \times 10^{9} / \mathrm{L}$ indicated a higher risk for MF transformation, consistent with both previous retrospective studies and the role of clonal megakaryocytes in the development of fibrosis. WBC counts $>15 \times 10^{9} / \mathrm{L}$ during the study were more common in patients who died.

With regard to thrombosis, bleeding and MF transformation, some treatment-related findings arose from the multivariate analysis. Both major thrombosis and arterial thrombosis were higher in the 'anagrelide' group (HR 1.68, CI 1.09 to $2.60, P=0.02$ and HR 1.91, CI 1.20 to 3.04 , $P=0.0067$, respectively), in line with results of the PT-1 trial, but not the ANAHYDRET study., The main statistical analysis of event rates performed in the overall group showed a lower event rate for major thrombosis and similar event rates for arterial thrombosis in the 'anagrelide' vs. the 'other CRT' groups. However, one has to take into consideration that on the one hand the age difference between the groups could influence the event rate analysis, and on the other hand the uncertainty of a post hoc multivariate analysis. The HR for venous thrombosis was lower with anagrelide treatment (HR 0.43, CI 0.15 to 1.21 ,
$P=0.12$, not significant), consistent with the PT- 1 trial and the ANAHYDRET study. A new finding was that the combination of anagrelide and smoking may increase the risk for arterial thrombosis vs. smoking plus other CRT (HR 3.18, CI 1.41 to $7.16, P=0.005$, not significant). Another unexpected finding was the increased combined thrombohemorrhagic risk in anagrelide-treated patients (vs. other CRT) with no prior vascular event (HR 2.20, CI 1.38 to 3.53, $P=0.001)$. The increased risk of hemorrhage with concomitant use of anagrelide and A-A therapy has been previously shown. ${ }^{9}$ The higher risk for MF in the anagrelide group, especially in women, is consistent with the event rate analysis and with the PT- 1 trial. ${ }^{9}$ The higher risk for MF transformation in patients diagnosed according to the PSVG criteria rather than the WHO criteria is in line with previous reports.

\section{Limitations}

EXELS is not a randomized study, thus treatment arms were not balanced for risk factors or baseline characteristics. The age difference between treatment groups was due to clinicians' treatment preferences. Assessments were only conducted as part of local routine clinical practice, therefore data were missing for variables such as laboratory values and mutation status. Events are few in ET, and even though EXELS is the largest prospective ET study performed, caution must be advocated in the interpretation of statistics, especially for PDEs with low numbers.

\section{Conclusions}

The EXELS study provides important observations that may influence clinical practice for patients with high-risk ET. It is the largest ever prospective real-world study in 
this condition. Overall, total thrombohemorrhagic event rates were low ( $<2.5 / 100$ patient-years), but a lower rate of venous thrombotic and a higher rate of hemorrhagic events were observed in the 'anagrelide' group. A post hoc multivariate analysis confirmed these differences, but also suggested a higher arterial thrombosis risk in anagrelidetreated patients, especially smokers. Transformation to MF was more frequent in PVSG-defined than in WHOdefined ET and was more frequent in the 'anagrelide' than in the 'other CRT' group. Transformation to AL and other malignancies was more common with other CRTs. A history of thrombohemorrhagic events, age $\geq 65$ years, cardiovascular risk factors, or hypertension were identified as baseline risk factors for thrombohemorrhagic events. These factors, time since diagnosis and an increase in platelet counts above normal were identified as risk factors for transformation to MF.

\section{Acknowledgments}

The authors would like to thank the contribution of all investigators who participated in this study (Appendix I). Under the direction of the authors, Donna Tillotson, PhD, employee of iMed Comms, an Ashfield Company, provided writing assistance for this publication. Editorial assistance in formatting, proofreading, copy editing, and fact checking was also provided by iMed Comms. Shire Pharmaceutical Development Ltd provided funding to iMed Comms for support in writing and editing this manuscript.

\section{Funding}

The study was funded by the Sponsor, Shire Pharmaceutical Development Ltd. The study was designed by the international EXELS steering committee $(G B, J-J K, C B, M G, L G, C H)$, chaired by $G B$, who is also the lead and corresponding author, and developed the final draft of the manuscript. $C B, M G, L G$, $\mathrm{CH}, J-J K$ all enrolled patients to the study, analyzed the data and critically reviewed the manuscript. HA contributed to the study management, interpretation of the data and critically reviewed the manuscript. $M H$ and JW undertook the statistical and multivariate analysis and critically reviewed the manuscript for data accuracy. All authors provided final approval of the manuscript, and agree to be accountable for all aspects of the work in ensuring that questions related to the accuracy or integrity of any part of the work are appropriately investigated and resolved. Although the Sponsor was involved in the design, collection, analysis, interpretation, and fact checking of information, the content of this manuscript, the ultimate interpretation, and the decision to submit it for publication in Haematologica was made by the authors independently.

\section{References}

1. Swerdlow SH, Campo E, Harris NL, et al. WHO classification of tumours of haemopoietic and lymphoid tissues, 2nd edition. 4th ed. Lyon: IARC Press; 2008.

2. Barbui T, Barosi G, Birgegard G, et al. Philadelphia-negative classical myeloproliferative neoplasms: critical concepts and management recommendations from European LeukemiaNet. J Clin Oncol. 2011; 29(6):761-770

3. Xagrid Summary of Product Characteristics, Shire Pharmaceuticals Ltd. 2014. (Available from; http://www. ema. europa. eu/ docs /en_GB/ document_library/EPAR _Product_Information/human/000480/WC5 00056557.pdf. Last accessed 9 February 2017)

4. Cortelazzo S, Finazzi G, Ruggeri $M$, et al. Hydroxyurea for patients with essential thrombocythemia and a high risk of thrombosis. N Engl J Med. 1995;332(17):11321136

5. Spivak JL, Hasselbalch $H$. Hydroxycarbamide: a user's guide for chronic myeloproliferative disorders. Expert Rev Anticancer Ther. 2011; 11(3):403-414

6. Cerquozzi S, Tefferi A. Blast transformation and fibrotic progression in polycythemia vera and essential thrombocythemia: a literature review of incidence and risk factors. Blood Cancer J. 2015; 5:e366.

7. Kiladjian JJ, Chevret S, Dosquet C, Chomienne C, Rain JD. Treatment of polycythemia vera with hydroxyurea and pipobroman: final results of a randomized trial initiated in 1980. J Clin Oncol. 2011; 29(29):3907-3913.

8. Gisslinger H, Gotic M, Holowiecki J, et al. Anagrelide compared with hydroxyurea in WHO-classified essential thrombocythemia: the ANAHYDRET Study, a randomized controlled trial. Blood. 2013; 121(10):17201728.

9. Harrison CN, Campbell PJ, Buck G, et al. Hydroxyurea compared with anagrelide in high-risk essential thrombocythemia. N Engl J Med. 2005;353(1):33-45.
10. Michiels IJ. Diagnostic criteria of the myeloproliferative disorders (MPD): essential thrombocythaemia, polycythaemia vera and chronic megakaryocytic granulocytic metaplasia. Neth J Med. 1997; 51(2):57-64.

11. Tefferi A, Thiele J, Orazi A, et al. Proposals and rationale for revision of the World Health Organization diagnostic criteria for polycythemia vera, essential thrombocythemia, and primary myelofibrosis: recommendations from an ad hoc international expert panel. Blood. 2007;110(4):1092-1097.

12. Collett D. Modeling survival data in medical research, 2nd edition. Boca Raton, FL: Chapman \& Hall/CRC; 2003.

13. Chu DK, Hillis CM, Leong DP, Anand SS, Siegal DM. Benefits and risks of antithrombotic therapy in essential thrombocythemia: a systematic review. Ann Intern Med. 2017;167(3):170-180.

14. Harrison C. Rethinking disease definitions and therapeutic strategies in essential thrombocythemia and polycythemia vera. Hematology Am Soc Hematol Educ Program. 2010;2010:129-134

15. Ejerblad E, Kvasnicka HM, Thiele J, et al. Diagnosis according to World Health Organization determines the long-term prognosis in patients with myeloproliferative neoplasms treated with anagrelide: Results of a prospective long-term followup. Hematology. 2013:18(1):13-18.

16. Laguna MS, Kornblihtt LI, Marta RF, Michiels JJ, Molinas FC. Effectiveness of anagrelide in the treatment of symptomatic patients with essential thrombocythemia. Clin Appl Thromb Hemost. 2000;6(3):157Clin

17. Storen EC, Tefferi A. Long-term use of anagrelide in young patients with essential thrombocythemia. Blood. 2001;97(4):863866.

18. Lahuerta-Palacios JJ, Bornstein R, FernandezDebora FJ, et al. Controlled and uncontrolled thrombocytosis. Its clinical role in essential thrombocythemia. Cancer. 1988;61(6):12071212

19. Schmitz S, Stauch M, Schlag R. Anagrelide for the treatment of thrombocythaemia in daily clinical practice: a post-marketing observational survey on efficacy and safety performed in Germany. Onkologie. 2010 33(1-2):39-44

20. Buxhofer-Ausch V, Steurer M, Sormann S, et al. Influence of platelet and white blood cell counts on major thrombosis - analysis from a patient registry in essential thrombocythemia. Eur J Haematol. 2016; 97(6):511 516.

21. Birgegard G, Bjorkholm M, Kutti J, et al Adverse effects and benefits of two years of anagrelide treatment for thrombocythemia in chronic myeloproliferative disorders. Haematologica. 2004;89(5):520-527.

22. Engel PI, Johnson H, Baughman RP, Richards AI. High-output heart failure associated with anagrelide therapy for essential thrombocytosis. Ann Intern Med. 2005, 143(4):311-313.

23. Valera MC, Parant O, Vayssiere C, Arnal JF Payrastre B. Essential thrombocythemia and pregnancy. Eur J Obstet Gynecol Reprod Biol. 2011:158(2):141-147.

24. Barbui T, Finazzi G, Carobbio A, et al. Development and validation of an International Prognostic Score of thrombosis in World Health Organization-essential thrombocythemia (IPSET-thrombosis). Blood. 2012;120(26):5128-5133

25. Passamonti F, Rumi E, Arcaini L, et al Prognostic factors for thrombosis, myelofibrosis, and leukemia in essential thrombocythemia: a study of 605 patients. Haematologica. 2008;93(11):1645-1651

26. Campbell PJ, Maclean $\mathrm{C}$, Beer PA, et al Correlation of blood counts with vascular complications in essential thrombo cythemia: analysis of the prospective PT1 cohort. Blood. 2012;120(7):1409-1411.

27. Lekovic D, Gotic M, Sefer D, Mitrovic-Ajtic $\mathrm{O}$, Cokic V, Milic N. Predictors of survival and cause of death in patients with essential thrombocythemia. Eur I Haematol 2015;95(5):461-466

28. Tefferi A, Gangat N, Wolanskyj A. The interaction between leukocytosis and other risk factors for thrombosis in essential thrombocythemia. Blood. 2007; 109(9):4105. 